Editor's Note: These short reviews of recent JNeurosci articles, written exclusively by students or postdoctoral fellows, summarize the important findings of the paper and provide additional insight and commentary. If the authors of the highlighted article have written a response to the Journal Club, the response can be found by viewing the Journal Club at www.jneurosci.org. For more information on the format, review process, and purpose of Journal Club articles, please see http://jneurosci.org/content/ preparing-manuscript\#journalclub.

\title{
Cortical Predictive Mechanisms of Auditory Response Attenuation to Self-Generated Sounds
}

\author{
Matthew G. Phillips, ${ }^{\star}$ (DStephen C. Lenzi, ${ }^{\star}$ and $\odot$ Jesse P. Geerts ${ }^{\star}$ \\ Sainsbury Wellcome Centre, University College London, London WC1E 6BT, United Kingdom \\ Review of Rummell et al.
}

The auditory system faces the challenging task of creating a useful and accurate representation of an ambiguous auditory scene: who or what generated which sound, and where did it come from (Bizley and Cohen, 2013)? Fundamental to this challenge is the ability of an organism to distinguish between self-generated and external sounds. For example, a prey animal that can distinguish between the sound of its own footstep and that of its predator greatly increases its chance of survival.

Studies in humans and a variety of model organisms have shown that auditory brain areas respond less strongly to self-generated sounds compared with external sounds of similar volume (Suga and Shimozawa, 1974; Poulet and Hedwig, 2002; Eliades and Wang, 2003, 2005; Baess et al., 2011), here referred to as auditory attenuation. It has been proposed that predictive processes play a role in auditory attenuation, but it remains unclear in which brain areas and by which mechanism this phenomenon arises. Evidence has been found for both cortical and subcortical contributions to auditory attenu-

Received Jan. 23, 2017; revised April 24, 2017; accepted April 26, 2017.

We thank the Gatsby Charitable Foundation and the Wellcome Trust for financial support.

*M.G.P., S.C.L., and J.P.G. contributed equally to this work.

Correspondence should be addressed to Jesse P. Geerts, Sainsbury

Wellcome Centre, 25 Howland Street, London W1T 4JG, UK. E-mail: jesse.geerts.14@ucl.ac.uk.

DOI:10.1523/JNEUROSCI.0216-17.2017

Copyright $\odot 2017$ the authors $\quad 0270-6474 / 17 / 375393-02 \$ 15.00 / 0$ ation. For example, work in the marmoset monkey has focused on cortical responses (Eliades and Wang, 2003, 2005), but early work in bats has shown auditory attenuation effects in the brainstem (Suga and Shimozawa, 1974). Furthermore, work in the cricket and electric fish has shown that this response is present in multiple modalities and many different brain areas (Poulet and Hedwig, 2002; Bays et al., 2006; Requarth and Sawtell, 2011). In their recent article, Rummell et al. (2016) sought to determine whether and how this phenomenon arises at the single-cell and circuit levels in mouse auditory cortex and the extent to which this arises through predictive mechanisms.

To investigate the neuronal basis of attenuation of self-generated auditory responses, Rummell et al. (2016) developed an experimental paradigm in mice. Mice were trained to operate a lever, which, when pressed, elicited a tone, thus avoiding vocalization-specific confounds that were present in previous studies in bats and monkeys (Suga and Shimozawa, 1974; Eliades and Wang, 2003, 2005). Using a variety of methods, Rummell et al. (2016) measured auditory neuronal responses when tones were presented either randomly or coincident with lever pressing and compared the results. Similar to previous macroscopic studies, the magnitude of the local field potential was shown to be reduced in response to self-generated sounds (Poulet and Hedwig, 2002; Eliades and Wang, 2003; Baess et al., 2011). Singleunit and multiunit probe recordings revealed that a subpopulation of neurons in auditory cortex exhibited strong attenuation to self-generated stimuli in both freely moving and head-fixed mice. Importantly, Rummell et al. (2016) addressed ambiguities from previous studies about how behavioral state and nonspecific motor effects influence the attenuation of neuronal responses by comparing responses to self-generated sounds and randomly generated sounds in epochs where the mice were moving.

Using clustering analysis on probe-acquired data, Rummell et al. (2016) then classified recorded neurons as putative pyramidal neurons or putative interneurons based on two action potential properties. Both putative neuronal types showed significant attenuation to self-generated sounds, while there was no significant difference in auditory attenuation between the two cell types. There was, however, a clear effect of cortical depth: neurons in deeper layers showed stronger attenuation to self-generated sounds than neurons in superficial layers. This laminar difference was particularly pronounced for putative interneurons. Given the heterogeneous distribution of interneuron cell types across cortical layers (Harris and Shepherd, 2015), it is plausible that these laminar differences indicate differential roles for particular subtypes of interneuron. Investigating these cell typespecific effects using genetic targeting, as 
has already been done in the case of habituation to sounds in auditory cortex (Kato et al., 2015; Natan et al., 2015), is likely to be a fruitful strategy for unraveling the local circuit mechanisms underlying auditory attenuation.

Although these experiments showed auditory attenuation in auditory cortex, the effect could have arisen from subcortical changes, cortical changes, or both. To tackle this question, the authors injected a virus expressing channelrhodopsin- 2 into auditory thalamus and replaced the auditory stimuli of their behavioral paradigm with self-generated or randomly generated optical stimulation of thalamocortical terminals in auditory cortex. When optical stimulation coincided with a lever press, cortical responses were attenuated compared with responses to random thalamic stimulation. This suggests that intracortical mechanisms are sufficient for attenuation. It should be noted, however, that a subcortical contribution was not ruled out, and previous work in the bat showed attenuation effects to self-generated vocalizations in the brainstem (Suga and Schlegel, 1972).

Having localized an intracortical contribution for the observed attenuation in auditory responses, Rummell et al. (2016) then recorded further upstream in the hippocampus. Here, the responses to selfgenerated sounds were greatly reduced relative to randomly generated sounds, such that effectively no response to selfgenerated sounds was seen. This suggests, as auditory information progresses up the processing hierarchy, the impact of predicting a stimulus on responses increases while predictable events are filtered out. While this hippocampal effect is particularly striking, its underlying mechanisms were not investigated. For example, it is unknown whether the responses from auditory cortex are routed via a monosynaptic connection or by a less direct pathway. This could be inferred indirectly from the data of Rummell et al. (2016) via the relative latency of responses: if the hippocampal responses occur markedly later than the cortical responses, it would be reasonable to assume an indirect pathway. Alternatively, the use of optogenetic or viral-mapping strategies could elucidate whether a monosynaptic connection is present and, when combined with extracellular recordings, whether it could be linked to the identity of the cells responding in auditory cortex. Identifying the functionconnectivity relationship underlying this phenomenon would provide a valuable insight into its neural mechanisms.

An important open question regards the nature of the observed attenuated responses: are they the result of task-related motor signals or part of a more general predictive mechanism for inferring the structure of the sensory environment? For example, stimulus-specific adaptation and deviance detection in auditory cortex would hold that the sensory responses owe to violations of regularities in the environment (Winkler et al., 2009; Natan et al., 2015). An alternative explanation is that reduced responses are the result of copies of motor signals from motor cortex, as has been observed in auditory cortex previously (Schneider et al., 2014). Rummell et al. (2016) set out to disentangle these hypotheses by manipulating the probability of occurrence of sounds to distinguish between "expected" (high probability) and "unexpected" (low-probability) self-generated or random sounds. They showed that the attenuated response to self-generated sounds was reduced but still present when the frequency of the tone was unexpected. This suggests that a mere difference between low-probability and high-probability sounds could not explain their results, but rather that the main effect is a direct consequence of the behavior of the animal, which seems to fit into the corollary discharge model but does not irrefutably prove that auditory attenuation is caused by signals from motor cortex. To address this, a first step should be to first disentangle specifically the anatomy of the corollary discharge pathways using viral tracing and then to investigate whether these pathways are necessary and sufficient for auditory attenuation under this paradigm. Rummell et al. (2016) provide numerous observations regarding auditory attenuation, extending current knowledge and addressing several controversies. The wide-ranging observations provide a welcome platform and paradigm from which to understand predictive processing in cortical areas. Future work should use these findings and paradigm to look further into the cortical circuitry underlying these processes.

\section{References}

Baess P, Horváth J, Jacobsen T, Schröger E (2011) Selective suppression of self-initiated sounds in an auditory stream: an ERP study. Psychophysiology 48:1276-1283. CrossRef Medline

Bays PM, Flanagan JR, Wolpert DM (2006) Attenuation of self-generated tactile sensations is predictive, not postdictive. PLoS Biol 4:e28. CrossRef Medline

Bizley JK, Cohen YE (2013) The what, where and how of auditory-object perception. Nat Rev Neurosci 14:693-707. CrossRef Medline

Eliades SJ, Wang X (2003) Sensory-motor interaction in the primate auditory cortex during self-initiated vocalizations. J Neurophysiol 89:2194-2207. CrossRef Medline

Eliades SJ, Wang X (2005) Dynamics of auditoryvocal interaction in monkey auditory cortex. Cereb Cortex 15:1510-1523. CrossRef Medline

Harris KD, Shepherd GM (2015) The neocortical circuit: themes and variations. Nat Neurosci 18:170-181. CrossRef Medline

Kato HK, Gillet SN, Isaacson JS (2015) Flexible sensory representations in auditory cortex driven by behavioral relevance. Neuron 88 : 1027-1039. CrossRef Medline

Natan RG, Briguglio JJ, Mwilambwe-Tshilobo L, Jones SI, Aizenberg M, Goldberg EM, Geffen MN (2015) Complementary control of sensory adaptation by two types of cortical interneurons. Elife 4:e09868. CrossRef Medline

Poulet JF, Hedwig B (2002) A corollary discharge maintains auditory sensitivity during sound production. Nature 418:872-876. CrossRef Medline

Requarth T, Sawtell NB (2011) Neural mechanisms for filtering self-generated sensory signals in cerebellum-like circuits. Curr Opin Neurobiol 21:602-608. CrossRef Medline

Rummell BP, Klee JL, Sigurdsson T (2016) Attenuation of responses to self-generated sounds in auditory cortical neurons. J Neurosci 36:12010 12026. CrossRef Medline

Schneider DM, Nelson A, Mooney R (2014) A synaptic and circuit basis for corollary discharge in the auditory cortex. Nature 513: 189-194. CrossRef Medline

Suga N, Schlegel P (1972) Neural attenuation of responses to emitted sound in echolocating bats. Science 177:82-84. CrossRef Medline

Suga N, Shimozawa T (1974) Site of neural attenuation of responses to self-vocalized sounds in echolocating bats. Science 183:1211-1213. CrossRef Medline

Winkler I, Denham SL, Nelken I (2009) Modeling the auditory scene: predictive regularity representations and perceptual objects. Trends Cogn Sci 13:532-540. CrossRef Medline 